
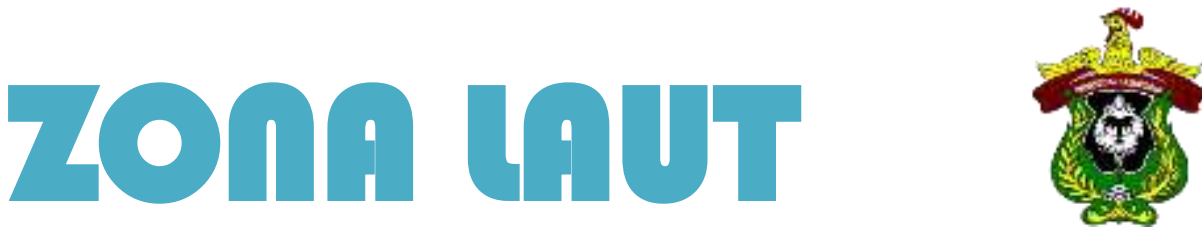

JURNAL INOVASI SAINS DAN TEKNOLOGI KELAUTAN

\title{
PENGARUH KONFIGURASI BRACE PADA STRUKTUR RANGKA DUA DIMENSI (2D)
}

\author{
*Indah Melati Suci dan Muhammad Zubair Muis Alie \\ Departemen Teknik Kelautan Fakultas Teknik Universitas Hasanuddin \\ *melati.sukma@gmail.com
}

\begin{abstract}
Abstrak
Struktur portal umumnya terdiri dari 2 dan 3 dimensi, beban-beban yang bekerja padanya juga bervariasi disesuaikan dengan tujuan dari portal itu sendiri digunakan. Struktur portal baik 2 atau 3 dimensi merupakan struktur yang tersusun dari balok dan kolom, sehingga umumnya diperkuat dengan batang diagonal yang disebut brace. Penelitian ini bertujuan untuk menganalisis pengaruh konfigurasi brace pada portal 2 dimensi. Struktur tersebut dimodelkan yang memilki konfigurasi brace yang bervariasi yang terdiri dari 5 model. Kondisi batas kelima model adalah sendi dan jepit dengan beban aksial titik yang konstan bekerja pada tiang vertikal. Dimensi portal, tegangan luluh, modulus elastisitas dan rasio poison diasumsikan konstan. Untuk pemodelan, perhitungan dan analisis, digunakan program bantu komputer yaitu SAP 2000. Hasil yang diperoleh berupa reaksi tumpuan, perpindahan titik dan deformasi dari kelima model.
\end{abstract}

Kata Kunci : Portal 2D, Konfigurasi Brace, SAP 2000.

\begin{abstract}
Abstrct
The portal structure generally consists of 2 and 3 dimensions, the loads that work on it are also varied adapted to the purpose of the portal itself is used. A portal structure of either 2 or 3 dimensions is a structure composed of beams and columns, so it is generally reinforced with a diagonal stem called a brace. The study aims to analyse the influence of brace configurations on 2-dimensional portals. The structure is modeled after a varied configuration of brace consisting of 5 models. The condition of the fifth boundary of the model is the joints and clamp with a constant axial load point working on the vertical pole. The portal dimensions, yield voltage, modulus of elasticity and poison ratio are assumed to be constant. For modeling, computation and analysis, used computer auxiliary programs namely SAP 2000. The results gained are focus reactions, point displacement and deformation of the five models.
\end{abstract}

Keywords: Portal 2D, Configuration of Brace, SAP 2000.

\section{PENDAHULAN}

Rangka batang adalah susunan elemen-elemen linear yang membentuk segitiga atau kombinasi segitiga, sehingga membentuk rangka yang dapat berubah bentuk apabila diberi beban eksternal tanpa adanya perubahan bentuk pada stu atau lebih batangnya. Prinsip utama yang mendasari penggunaan rangka batang sebagai struktur pemikul beban adalah penyusunan elemen menjadi konfigurasi segitiga yang menghasilkan bentuk stabil. Pada bentuk segiempat atau bujursangkar, bila struktur tersebut diberi beban, maka akan terjadi deformasi masif dan menjadikan struktur tak stabil. Bila struktur ini diberi beban, maka akan membentuk suatu mekanisme runtuh (collapse).Pada struktur stabil, gaya eksternal menyebabkan timbulnya gaya pada batang-batang. Gaya-gaya tersebut adalah gaya tarik dan tekan murni. Lentur (bending) tidak akan terjadi selama gaya eksternal berada pada titik nodal (titik simpul). Bila susunan segitiga dari batang-batang adalah bentuk stabil, maka sembarang susunan segitiga juga membentuk struktur stabil dan kukuh [6]. Portal merupakan salah satu struktur rangka batang yang banyak di jumpai. Portal terdiri dari elemen-elemen balok dan kolom. Elemen-elemen balok dan kolom terhubung secara kaku pada satu titik. Umumnya system copyright is published under Lisensi Creative Commons Atribusi 4.0 Internasional. 
struktur portal digunakan bila beban grafitasi lebih dominan dari pada beban lateral akibat gaya gempa maupun angina. System struktur portal identic dengan struktur rangka yang mana juga terdiri dari elemenelemen balok dan kolom yang saling terhubung pada sambungan yang kaku. Penelitian yang terkait dengan analisa struktur portal dan rangka batang diantaranya adalah Muis Alie [1] menganalisis kekuatan batas struktur jacket platform dengan mempertimbangkan konfigurasi elemen brace dalam kolom. Analisis kekuatan batas tatap pada platform offshore dengan mempertimbangan pengaruh konfigurasi simetris dan asimetris oleh Muis Alie [2]. Yang [3] mengusulkan kinerja runtuh seismic dari platform lepas pantai pada jacket dengan varian waktu model korosi zonal. Pengaruh bentuk simetris dan asimetris pada kekuatan tekuk pada platform lepas pantai oleh Muis Alie [4]. Tian [5] memaparkan desain optimasi topologi untuk struktur jacket platform lepas pantai.

\section{METODE}

Metode yang digunakan pada penelitian ini yaitu dengan menggunakan software SAP 2000 kita dapat menganalisis reaksi pada batang dan reaksi pada titk tumpuan dengan memberikan beban sebesar 40 ton. Model portal yang digunakan sebanyak 2 model dimana dapat digambarkan sebagai berikut:

Model 1
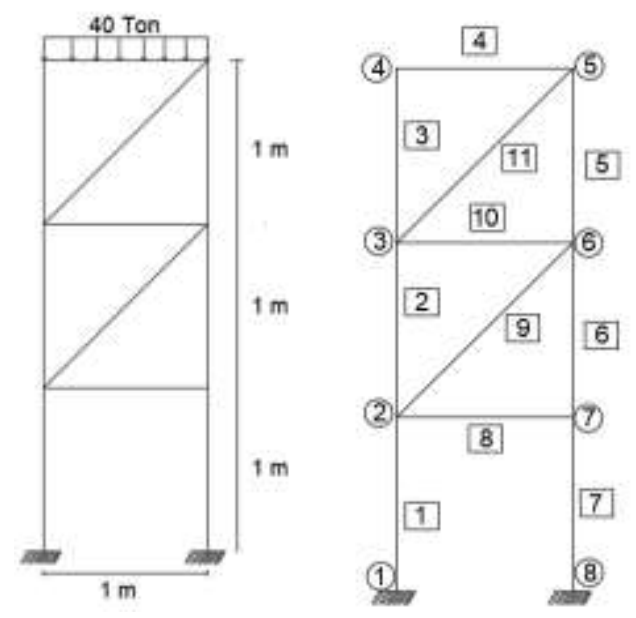

(Model 1a)
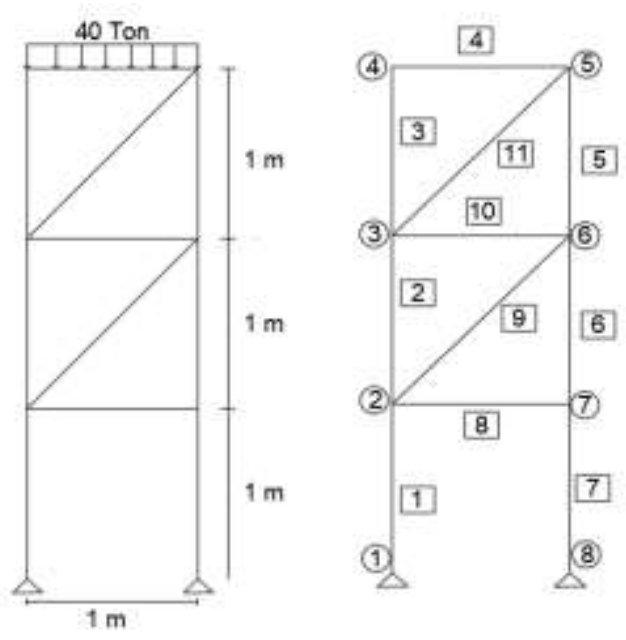

(Model 1b)

Gambar 1. Model 1

Model 2
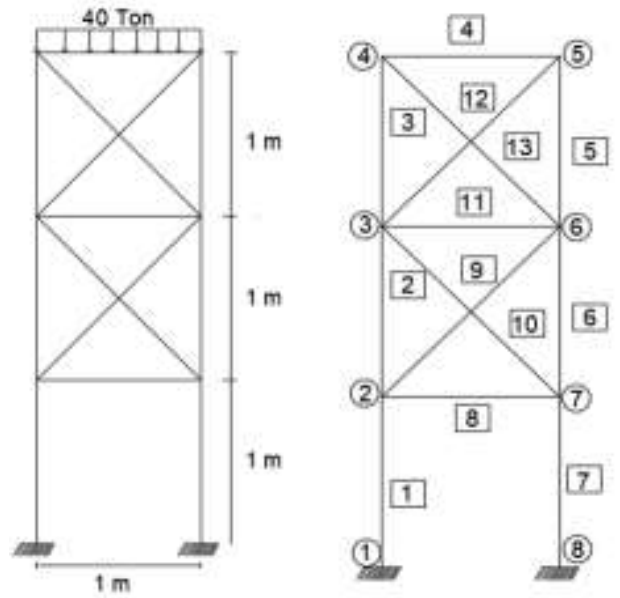

(Model 2a)
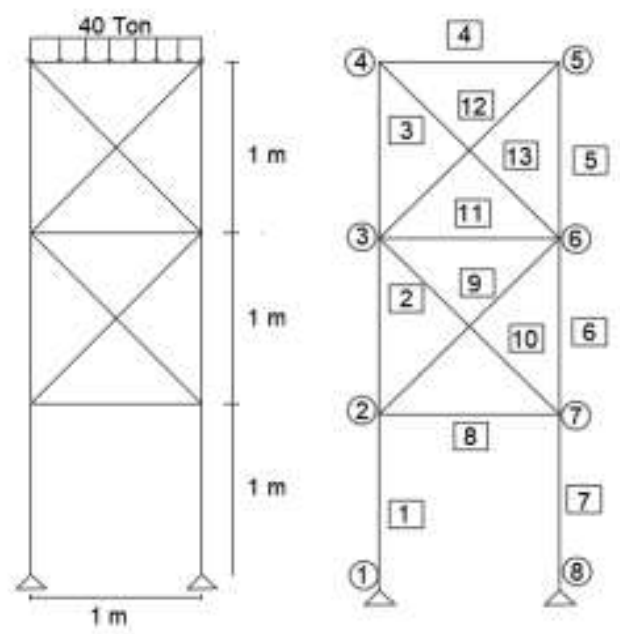

Gambar 2. Model 2 


\section{HASIL DAN PEMBAHASAN}

Pada rangka batang atau portal, setiap elemen dianggap tergabung pada titik hubung sendi. Batang-batang disusun sedemikian rupa sehingga semua beban dan reaksi hanya terjadi pada titk hubung tersebut. Pada analisis ini beban yang diberikan sebesar 40 ton.

Tabel 1. Reaksi tumpuan model 1a

\begin{tabular}{lllllll}
\hline Joint & F1 & F2 & F3 & M1 & M2 & M3 \\
& Ton & Ton & Ton & Ton-m & Ton-m & Ton-m \\
\hline 1 & 0.071 & 0 & 20.22 & 0 & -0.09222 & 0 \\
8 & -0.071 & 0 & 19.78 & 0 & -0.12775 & 0 \\
\hline
\end{tabular}

Tabel 2. Reaksi tumpuan model $1 \mathrm{~b}$

\begin{tabular}{|c|c|c|c|c|c|c|}
\hline \multirow[t]{2}{*}{ Joint } & $\mathrm{F} 1$ & $\mathrm{~F} 2$ & F3 & M1 & M2 & M3 \\
\hline & Ton & Ton & Ton & Ton-m & Ton-m & Ton-m \\
\hline 1 & 0.0457 & 0 & 20 & 0 & 0 & 0 \\
\hline 8 & -0.0457 & 0 & 20 & 0 & 0 & 0 \\
\hline
\end{tabular}

Pada model 1 terdiri dari terdiri dari delapan node dan sebelas elemen dimana pada model 1a menggunakan tumpuan jepit dan model $1 \mathrm{~b}$ menggunakan tumpuan sendi. Analisis struktur ranga dilakukan dengan menggunakan metode numerik. Dua model struktur frame dipertimbangkan dalam analisis dengan hasil reaksi tumpuan pada model $1 \mathrm{a}$ dan $1 \mathrm{~b}$. Reaksi tumpuan tersebut terdapat pada titik 1 dan 8 diamana rekasi tumpuan yang terjadi di titik 1 dan titik 8 pada kedua model berbeda. Hal lain terjadi perbedaan adalah momen M2 dimana pada model 1a terjadi momen, sementara model $1 \mathrm{~b}$ momen tidak terjadi. Hal ini disebabkan kondisi tumpuan yang berbeda antara model 1a dan model $1 \mathrm{~b}$.

Tabel 3. Reaksi tumpuan model 2a

\begin{tabular}{lllllll}
\hline Joint & F1 & F2 & F3 & M1 & M2 & M3 \\
& Tonf & Tonf & Tonf & Tonf-m & Tonf-m & Tonf-m \\
\hline 1 & 0.2472 & 0 & 20 & 0 & 0.09089 & 0 \\
8 & -0.2472 & 0 & 20 & 0 & -0.09089 & 0 \\
\hline
\end{tabular}

Tabel 4. Reaksi tumpuan model $2 \mathrm{~b}$

\begin{tabular}{lllllll}
\hline Joint & F1 & F2 & F3 & M1 & M2 & M3 \\
& Tonf & Tonf & Tonf & Tonf-m & Tonf-m & Tonf-m \\
\hline 1 & 0.1461 & 0 & 20 & 0 & 0 & 0 \\
8 & -0.1461 & 0 & 20 & 0 & 0 & 0 \\
\hline
\end{tabular}

Pada model 2 terdiri dari terdiri dari delapan node dan tigabelas elemen dimana pada model 2a menggunakan tumpuan jepit dan model $2 \mathrm{~b}$ menggunakan tumpuan sendi. Analisis struktur ranga dilakukan dengan menggunakan metode numerik. Dua model struktur frame dipertimbangkan dalam analisis dengan hasil reaksi tumpuan pada model $2 \mathrm{a}$ dan $2 \mathrm{~b}$. Reaksi tumpuan tersebut terdapat pada titik 1 dan 8 diamana rekasi tumpuan yang terjadi di titik 1 dan titik 8 pada kedua model berbeda. Hal lain terjadi perbedaan adalah momen M2 dimana pada model 2a terjadi momen, sementara model $2 \mathrm{~b}$ momen tidak terjadi. Hal ini disebabkan kondisi tumpuan yang berbeda antara model $2 \mathrm{a}$ dan model $2 \mathrm{~b}$.

Tabel 5. Perpindahan titik model 1a

\begin{tabular}{lllllll}
\hline Joint & $\mathrm{U} 1$ & $\mathrm{U} 2$ & $\mathrm{U} 3$ & $\mathrm{R} 1$ & $\mathrm{R} 2$ & \multicolumn{2}{l}{$\mathrm{R} 3$} \\
& $\mathrm{~m}$ & $\mathrm{~m}$ & $\mathrm{~m}$ & Radians & Radians & Radians \\
\hline 4 & 0.000218 & 0 & -0.000447 & 0 & 0.000151 & 0 \\
5 & 0.000369 & 0 & -0.000669 & 0 & -0.000282 & 0 \\
\hline
\end{tabular}


Tabel 6. Perpindahan titik model $1 \mathrm{~b}$

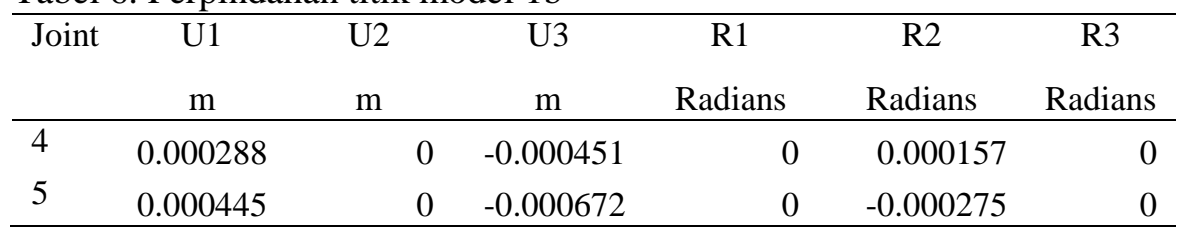

Perpindahan titik pada model 1 disajikan pada table 5 dan 6. Dari tabel tersebut, perpindahan terjadi pada arah $\mathrm{x}$ dan $\mathrm{z}$ untuk translasi dan y untuk rotasi. Hal ini diamati bahwa perpindahan yang sangat kecil baik translasi maupun rotasi pada tumpuan jepit maupun sendi.

Tabel 7. Perpindahan titik model 2a

\begin{tabular}{lllllll}
\hline Joint & $\mathrm{U} 1$ & $\mathrm{U} 2$ & $\mathrm{U} 3$ & $\mathrm{R} 1$ & $\mathrm{R} 2$ & $\mathrm{R} 3$ \\
& $\mathrm{~m}$ & $\mathrm{~m}$ & $\mathrm{~m}$ & Radians & Radians & Radians \\
\hline 4 & 0.00004 & 0 & -0.000412 & 0 & -0.000007833 & 0 \\
5 & 0.000009421 & 0 & -0.000586 & 0 & -0.000346 & 0 \\
\hline
\end{tabular}

Tabel 8. Perpindahan titik model $2 \mathrm{~b}$

\begin{tabular}{|c|c|c|c|c|c|c|}
\hline \multirow[t]{2}{*}{ Joint } & U1 & $\mathrm{U} 2$ & U3 & R1 & R2 & R3 \\
\hline & $\mathrm{m}$ & $\mathrm{m}$ & $\mathrm{m}$ & Radians & Radians & Radians \\
\hline 4 & 0.00004 & 0 & -0.000412 & 0 & -0.00007919 & 0 \\
\hline 5 & 0.000009425 & 0 & -0.000586 & 0 & -0.000346 & 0 \\
\hline
\end{tabular}

Perpindahan titik pada model 2 disajikan pada table 7 dan 8. Dari table tersebut, perpindahan terjadi pada arah $\mathrm{x}$ dan $\mathrm{z}$ untuk translasi dan y untuk rotasi. Hal ini diamati bahwa perpindahan yang sangat kecil baik translasi maupun rotasi pada tumpuan jepit maupun sendi.

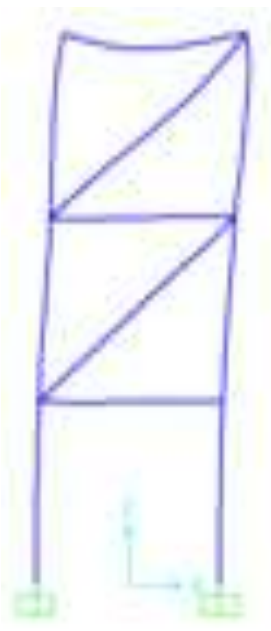

(Model 1a)

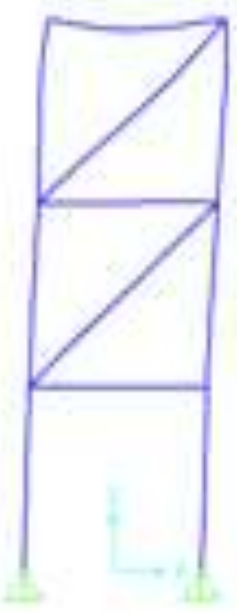

(Model 1b)

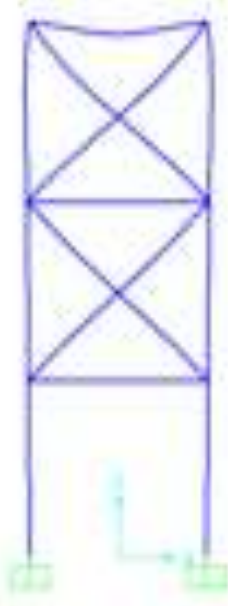

(Model 2a)

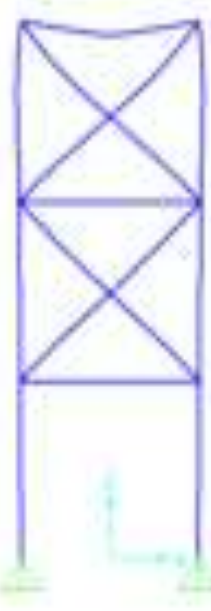

(Model 2b)

Gambar 3. Deformasi

Gambar 3 menunjukkan deformasi dari 2 model struktur rangka portal 2D. Hal ini diamati bahwa deformasi lebih besar terdapat pada model 1 dan terkecil pada model 2. Pengaruh kondisi tumpuan dan konfigurasi brace pada kedua model sangat signifikan dengan beban yang konstan.

\section{KESIMPULAN}

Analisis rangka batang portal 2D dengan menggunakan metode numerik aplikasi software telah dilakukan dengan beberapa model. Variasi brace dan kondisi tumpuan yang ada pada struktur portal 2D juga dilakukan dengan beban distribusi aksial yang konstan. Berdasarkan hasil analisa diperoleh bahwa reaksi tumpuan, 
perpindahan titik dan deformasi berbeda baik untuk model 1 dan model 2 dengan membandingkan keduanya. Perbedaan lain juga diperoleh pada nilai moment, dimana nilai moment untuk struktur portal 2D dengan tumpuan jepit memiliki nilai, disisi lain model dengan tumpuan sendi nilai moment tidak ada. Pengaruh brace sangat signifikan tidak hanya reaksi tumpuan, tetapi juga perpindahan titik serta deformasi yang terjadi. Reaksi tumpuan yang berbeda untuk kedua model termasuk perpindahan titik dan deformasi yang lebih besar terdapat pada model 1 dan terkecil terdapat pada model 2. Pengaruh kondisi tumpuan untuk dua model sangat signifikan dengan beban yang konstan.

\section{UCAPAN TERIMA KASIH}

Penelitian ini dapat dilaksanakan dengan baik berkat bantuan dari berbagai pihak, untuk itu peneliti mengucapkan terima kasih kepada Kepala Laboratorium Struktur Ocean Structure Analysis Research Laboratory (OSAREL) dan anggota Labo Osarel yang telah memberikan motivasi dan berbagi ilmu kepada peneliti dalam melaksanakan kegiatan ini.

\section{DAFTAR PUSTAKA}

[1] Muis Alie M Z, Icon Yan Franchover O, Achmad Yasir B, Rachman T and Juswan "Comparative Study of Structural Geometric to the Ultimate Strenght on Fixed Jacket Platform”, 2017

[2] Muis Alie M Z "The Effect Of Symmetrical and Asymmetrical Configuration Shapes On Buckling and Fatigue Strenght Analysis of Fixed Offshore Platform", 2016

[3] Yang Y, Qingjin Wu, Zheng He, Ziyue Jia, Xiawei Zhang,"Seismic Collapse Performance of Jacket Offshore Platform with Time-Variant Zonal Corrosion Model", 2019

[4] Muis Alie M Z, Juswan, Sifiani Daud, Widya Tami and Ratnawati "The Effect Symmetrical and Asymmetrical Shape in Buckling Strenght on Fixed Offshore Platform”, 2015

[5] Tian X, Wang Q, Liu G, Liu Y and Xie Y,"Topologi Optimization Design for offshore Platform Jacket Structure", 2019

[6] Schodeck, "Struktur", Pt Refika Aditama,Bandung, 1998 